abstracts of eight annual conferences. RCTs reporting administration of probiotics in adults with functional constipation were included. Two reviewers independently performed the screening of articles, data extraction, and risk of bias assessment. Data were synthesised using weighted or standard mean differences for all relevant outcomes using a random effects model. Publication bias was assessed via funnel plots and the Egger's test.

Results 657 records were identified, of which 14 were eligible (1,347 patients). Probiotics significantly reduced whole gut transit time by $11.9 \mathrm{~h}(95 \% \mathrm{CI}:-18.4$ to $-5.4 ; \mathrm{p}=0.0003)$. They also significantly reduced right and left colonic transit times by $5.7 \mathrm{~h}(95 \% \mathrm{CI}:-9.9$ to $-1.6 ; \mathrm{p}=0.007)$ and $5.1 \mathrm{~h}$ (95\% CI: -9.6 to $-0.6 ; p=0.03)$, respectively. Probiotics significantly increased stool frequency by 1.1 bowel movements per week (95\% CI: 0.7 to $1.5 ; \mathrm{p}<0.0001)$ with a number to treat (NNT) of 2, but there was significant heterogeneity $\left(\mathrm{I}^{2}=79 \%\right.$; $<0.0001$ ). Probiotics resulted in softer stool consistency (standardised mean difference, SMD $=+0.5,95 \% \mathrm{CI}: 0.3$ to $0.8 ; \mathrm{p}$ $=0.0001)$ with a NNT of 3. Bloating (SMD $=-0.6,95 \%$ CI: 1.2 to $-0.01 ; \mathrm{p}=0.04)$ and flatulence $(\mathrm{SMD}=-0.4,95 \% \mathrm{CI}$ : 0.7 to $-0.1 ; p=0.01$ ) were also significantly reduced. No serious adverse events were reported following probiotic administration, and compliance was over 95\%. There was no statistically significant funnel plot asymmetry found $(\mathrm{p}=0.271)$, suggesting no evidence of publication bias.

Conclusion Probiotics significantly improve gut transit time, stool frequency and consistency, and constipation-related symptoms, and are associated with low risk of adverse events and high rates of compliance. Probiotics should thus be considered as an alternative treatment for functional constipation.

Disclosure of Interest E. Dimidi Grant/research support from: Nestec Ltd, S. Christodoulides Grant/research support from: Nestec Ltd, K. Fragkos: None Declared, S. M. Scott: None Declared, K. Whelan: None Declared.

\section{PWE-165 A REAL WORLD STUDY TO DESCRIBE THE PATIENT PATHWAYS AND NHS RESOURCE USE ASSOCIATED WITH THE MANAGEMENT OF IRRITABLE BOWEL SYNDROME (IBS) IN UK CLINICAL PRACTICE}

${ }^{1}$ C Caldwell ${ }^{*},{ }^{2} \mathrm{~J}$ Collins, ${ }^{3} \mathrm{M}$ Rance, ${ }^{4} \mathrm{R}$ Dew. ${ }^{1}$ Swan Lane Medical Centre, Bolton, UK; ${ }^{2}$ NIHR Greater Manchester Comprehensive Local Research Network, Manchester, UK; ${ }^{3}$ Almirall UK, Uxbridge, UK; ${ }^{4} \mathrm{pH}$ Associates Ltd, Marlow, UK

\subsection{6/gutjnl-2014-307263.425}

Introduction Irritable bowel syndrome (IBS) is often a diagnosis of exclusion, with poor diagnosis coding in primary care. This makes identification of eligible research participants challenging.

We present the methodology development of a multi-centre, observational, retrospective research study ongoing in primary care, designed to overcome the challenges of IBS patient identification.

Methods Study feasibility was conducted by $\mathrm{pH}$ Associates (research consultancy; study coordinators) for Almirall UK Ltd (Sponsor) using medical opinion, clinical coding searches and NIHR Clinical Research Network expertise. FARSITE, a software tool for identification of research participants in primary care developed by the Greater Manchester Comprehensive Local Research Network and North West e-Health, was used to screen anonymised primary care records for potential eligible patients. Search criteria: patients aged 18-60; combination READ code symptoms indicative of IBS and prescription of IBS drugs 01/01/ 2009-31/12/2011. GP practices with eligible patients were invited to participate, with GPs reviewing clinical records of the FARSITE-generated list of patients to apply full eligibility criteria for final patient selection.

Inclusion criteria: medical diagnosis of IBS or meeting ROME III criteria; provision of consent. Exclusion Criteria: diagnosis excluding IBS; IBS symptoms secondary to other condition; IBS medications for non-GI symptoms. The study is ongoing in 8 GP practices in Salford and Greater Manchester (Ethical approval 13/LO/0692).

Results FARSITE feasibility search using READ code for IBS identified $50(0.02 \%)$ patients. Combining READ codes with symptom and prescriptions criteria selected 4714 (1.9\%) From these, 3 GP practices each screened 10 random patient records for eligibility and 12/30 (40\%) were found eligible. Eligibility READ codes were revised following feasibility.

Following study approvals, FARSITE identified 1089 potential eligible patients at the 8 participating practices, of which 297 (27.3\%) were eligible and approached for consent for participation. Main reasons for non-eligibility were symptom characteristics not meeting ROME III criteria or not confirmed as IBS by medical opinion.

Conclusion Identification of patients with IBS using READ code is sub-optimal in primary care. A combination search of READ codes with symptom and prescription data via FARSITE has enabled potential participants to be identified with a reasonable screening failure rate. FARSITE is a valuable research tool aiding study feasibility by reducing the need for manual patient identification.

Disclosure of Interest I. Caldwell: None Declared, J. Collins: None Declared, M. Rance Employee of: Almirall UK Limited, R. Dew Conflict with: Commissioned by Almirall UK to provide research design, conduct analysis and scientific editorial services.

\section{PWE-166 IS RESPONSE TO LINACLOTIDE AFTER 4 WEEKS OF TREATMENT PREDICTIVE OF 12-WEEK IMPROVEMENT?}

${ }^{1} \mathrm{~W}$ Chey, ${ }^{2} \mathrm{~B}$ Lavins, ${ }^{3} \mathrm{~S}$ Shiff, ${ }^{2} \mathrm{~J}$ MacDougall, ${ }^{2} \mathrm{C}$ Kurtz, ${ }^{2} \mathrm{M}$ Currie, ${ }^{2} \mathrm{~J}$ Johnston*. ${ }^{1}$ University of Michigan, Ann Arbor, MI, USA; ${ }^{2}$ Ironwood Pharmaceuticals, Cambridge, MA, USA;

${ }^{3}$ Forest Research Institute, Jersey City, NJ, USA

\subsection{6/gutjpl-2014-307263.426}

Introduction Linaclotide is a minimally absorbed guanylate cyclase $\mathrm{C}$ agonist approved in the US and EU for irritable bowel syndrome with constipation (IBS-C). A question for prescribing physicians is whether to continue linaclotide in patients who do not improve during the early weeks of therapy. This post-hoc analysis assessed if response to linaclotide at Week 4 predicts Week 12 improvement, and if linaclotide should be continued in IBS-C patients not responding by Week 4 .

Methods Pooled data from 2 Phase 3 IBS-C trials of linaclotide were analysed. For Degree of Relief of IBS Symptoms, Degree of Relief of Abdominal Pain, and Spontaneous Bowel Movement $[\mathrm{SBM}]$ frequency, a patient's Week-4 clinical response was used to predict improvement at Week 12. For the purposes of determining a patient's Week-4 response, the 7-point balanced Degree of Relief scale was collapsed into 3 categories: Improved (completely, considerably, or somewhat relieved), Unchanged, and Worse (somewhat worse, considerably worse, or as bad as I can imagine) compared with baseline. For SBM frequency, a dichotomous end point was used: SBMs increased by $\geq 2 /$ week or not increased by $\geq 2 /$ week from baseline.

Results The proportion of patients who had response at Week 4 was significantly greater for linaclotide- vs placebo-treated 
patients: 72 vs. $47 \%$ for Degree of Relief of IBS Symptoms, 70 vs. $47 \%$ for Degree of Relief of Abdominal Pain, and 59\% vs $33 \%$ for SBM frequency (all comparisons: $\mathrm{p}<0.0001$ ). For all parameters, most linaclotide-treated patients $(\geq 70 \%)$ who had response at Week 4 were improved at Week 12. For linaclotidetreated patients whose symptoms were unchanged at Week 4 for Degree of Relief of IBS Symptoms and Degree of Relief of Abdominal Pain, 36 and 39\% were improved at Week 12, vs. 19 and $21 \%$ of the placebo group, respectively $(\mathrm{p}<0.05$ ). For SBM frequency, $30 \%$ of linaclotide-treated patients vs. $17 \%$ of placebo-treated patients without response at Week 4 were improved (SBMs $\geq 2)$ at Week $12(\mathrm{p}<0.05)$.

Conclusion Patients whose IBS symptoms improved after 4 weeks with linaclotide were likely to maintain improvement. At least $30 \%$ of linaclotide patients who were unchanged at Week 4 experienced symptom improvement by Week 12 . The significant differences between linaclotide and placebo in the percentage of patients improved at Week 12 who were unchanged at Week 4 indicates that in some patients $\geq 1$ month of linaclotide therapy may be required for improvement. Hence, an initial course of linaclotide therapy in patients with IBS-C shou.ld be $>4$ weeks.

Study funded by Forest Laboratories, Inc., and Ironwood Pharmaceuticals, Inc.

Disclosure of Interest W. Chey Consultant for: Ironwood Pharmaceuticals, Forest Research Institute, B. Lavins Shareholder of: Ironwood Pharmaceuticals, Employee of: Ironwood Pharmaceuticals, S. Shiff Shareholder of: Forest Research Institute, Employee of: Forest Research Institute, J. MacDougall Shareholder of: Ironwood Pharmaceuticals, Employee of: Ironwood Pharmaceuticals, C. Kurtz Shareholder of: Ironwood Pharmaceuticals, Employee of: Ironwood Pharmaceuticals, M. Currie Shareholder of: Ironwood Pharmaceuticals, Employee of: Ironwood Pharmaceuticals, J. Johnston Shareholder of: Ironwood Pharmaceuticals, Employee of: Ironwood Pharmaceuticals.

\section{PWE-167 EFFECT OF LINACLOTIDE ON IBS-QOL SEXUAL SUBSCALE SCORES IN PATIENTS WITH IRRITABLE BOWEL SYNDROME WITH CONSTIPATION: RESULTS FROM 2 PHASE 3 TRIALS}

${ }^{1} \mathrm{M}$ Currie, ${ }^{2} \mathrm{~S}$ Shiff, ${ }^{1} \mathrm{X}$ Hao, ${ }^{2} \mathrm{R}$ Carson, ${ }^{1} \mathrm{M}$ Baird, ${ }^{1} \mathrm{f}$ Johnston*. 'Ironwood Pharmaceuticals, Cambridge, MA, USA; ${ }^{2}$ Forest Research Institute, Jersey City, NJ, USA

\subsection{6/gutjnl-2014-307263.427}

Introduction Linaclotide is a minimally absorbed guanylate cyclase-C agonist approved for treatment of IBS with constipation (IBS-C). IBS often results in diminished quality of life (QOL), including decreased sexual desire and activity. This post- hoc analysis aimed to determine if linaclotide treatment improved IBS-QOL sexual subscale scores in IBS-C patients, compared to placebo.

Methods Data from 2 randomised, double-blind Phase 3 linaclotide trials in IBS-C were pooled. The IBS-QOL was administered at baseline and Week 12. The sexual subscale includes items on difficulty with sexual activity and reduced sexual desire, both rated on a 5 -point scale $(1=$ not at all, $2=$ slightly, $3=$ moderately, $4=$ quite a bit, $5=$ extremely/a great deal); the sum of both items is scaled to 0 (worst) to 100 (best). Changes in the scores from baseline to Week 12 were compared for linaclotide- vs placebo-treated patients in the intent-to-treat (ITT) population and the Impaired Sexuality (IS) subgroup (baseline sexual subscale scores $\leq 50$ ).

Results Of 1598 ITT patients with baseline sexual subscale scores, $522(33 \%)$ had a score $\leq 50$ indicating significant impact of IBS on sexual desire and activity (females: 484/1439 [34\%]; males: 38/159 [24\%]). At Week 12, linaclotide significantly improved change-from-baseline sexual subscale scores vs placebo in the ITT population and IS subgroup (Table, $\mathrm{p}<0.001$ for both). Although baseline scores for males were higher (better) than for females, improvement vs placebo for males was similar to females in the ITT population and greater for the IS subgroup. However, the male sample size was too small to establish statistical significance.

Conclusion Linaclotide treatment significantly improves IBS-QOL sexual subscale scores in IBS-C patients compared with placebo, in both the total population and in patients with impaired sexuality at baseline.

Study funded by Forest Laboratories, Inc., and Ironwood Pharmaceuticals, Inc.

Disclosure of Interest M. Currie Shareholder of: Ironwood Pharmaceuticals, Employee of: Ironwood Pharmaceuticals, S. Shiff Shareholder of: Forest Research Institute, Employee of: Forest Research Institute, X. Hao Shareholder of: Ironwood Pharmaceuticals, Employee of: Ironwood Pharmaceuticals, R. Carson Shareholder of: Forest Research Institute, Employee of: Forest Research Institute, M. Baird Shareholder of: Ironwood Pharmaceuticals, Employee of: Ironwood Pharmaceuticals, J. Johnston Shareholder of: Ironwood Pharmaceuticals, Employee of: Ironwood Pharmaceuticals.

\section{PWE-168 IS THERE A RELATIONSHIP BETWEEN IRRITABLE BOWEL SYNDROME SYMPTOMS AND SMALL BOWEL BACTERIAL OVERGROWTH?}

${ }^{1} J$ R Hayman*, 'G Pickering, ${ }^{2} D S$ Sanders. ${ }^{1} G$ Physiology, Northern General Hospital; ${ }^{2}$ Gastroenterology and Liver Unit, Royal Hallamshire Hospital, Sheffield, UK

10.1136/gutjnl-2014-307263.428

\begin{tabular}{lllllllll}
\multicolumn{2}{l}{ Abstract PWE-167 Table 1} & IBS-QOL sexual subscale results \\
\hline & Placebo (ITT) & Linaclotide (ITT) & Change from baseline $\Delta$ & $P$-value (ITT) & Placebo (IS) & Linaclotide (IS) & Change from baseline $\Delta$ & $P$-value (IS) \\
\hline Overall (n) & 795 & 803 & 5.2 & $<0.0001^{*}$ & 249 & 273 & 7.2 & $0.0007^{*}$ \\
Baseline & $68.9(31.9)$ & $66.9(30.9)$ & & & $27.2(17.8)$ & $29.5(17.7)$ & & \\
Week 12 & $79.7(25.9)$ & $83.1(23.6)$ & & $57.8(29.9)$ & $67.9(28.1)$ & & \\
Females (n) & 706 & 733 & 5.2 & $<0.0001^{*}$ & 228 & 256 & 6.7 & $0.0016^{*}$ \\
Baseline & $68.0(32.3)$ & $66.1(31.1)$ & & & $26.6(17.8)$ & $29.5(17.8)$ & & \\
Week 12 & $79.8(25.8)$ & $83.2(23.4)$ & & $58.5(30.2)$ & $68.6(27.7)$ & & \\
Males (n) & 89 & 70 & 4.2 & $0.3129^{*}$ & 21 & 17 & 10.2 & $0.2389^{*}$ \\
Baseline & $76.3(28.1)$ & $74.5(28.7)$ & & $32.7(16.5)$ & $30.1(17.7)$ & & \\
Week 12 & $78.9(26.7)$ & $81.5(26.0)$ & & & $50.0(25.7)$ & $57.8(33.2)$ & & \\
\hline
\end{tabular}

Data are mean (SD)

${ }^{*} P$-values based on change-from-baseline treatment difference for linaclotide vs placebo (ANCOVA) 